https://doi.org/10.24297/jal.v11i.8691

\title{
Multilingualism in Hong Kong's formal and informal settings: A brief historical review of the development from the early 1900 s to the late 2010 s
}

\author{
Bernie Chun Nam MAK, PhD \\ School of Continuing Education, Hong Kong Baptist University, Hong Kong, China \\ bcnmak@staff.hkbu.edu.hk
}

\begin{abstract}
This article aims at tracing back the making of multilingualism in Hong Kong from a socio-historical viewpoint. It primarily illustrates the linguistic profiles of Cantonese, English, and Putonghua in official domains throughout the colonial period and after the 1997 handover, secondarily describing their roles in Hongkongers' daily life. The situation of other minor languages is mentioned in passing. The snapshots reveal that a) Cantonese has developed to be a powerless lingua franca of Hongkongers, b) English has become a powerful second language with high economic value that hugely outweighs Cantonese, and that c) Putonghua has been similar to a foreign language despite its official status on the mainland. Other heritage languages of ethnic minorities have existed since the early colonial period, but they have never entered the mainstream or vastly impacted the three dominating languages. The discussion concludes that Hong Kong has yet to be a typical multilingual metropolis where citizens are fluent or native in multiple languages. It is still fluctuating in between monolingualism and multilingualism, however, showing an inclination to the latter.
\end{abstract}

Keywords: Hong Kong, linguistic situation, multilingualism, language planning, language attitude

\section{Introduction}

While academics and commentators have seldom reached a consensus on Hong Kong students' language standards, few people will disagree that nowadays, the three languages of the city are Cantonese, English, and Putonghua. This linguistic situation, together with the occasional mix with other languages, has made Hong Kong a potential multilingual society where various languages play their roles in different contexts.

Academic discourses about Hong Kong multilingualism have concentrated on the educational and interactional sociolinguistic aspects. Although multilingualism does not just concern people's linguistic competence (Grosjean 2010; cf. Bloomfield 1933), studies on Hong Kong multilingualism have been tied up with education, especially the medium of instruction (MoI) (e.g., Lin \& Man 2009). As multilingualism presupposes the use of mixed code (Pennington 1998), there has also been a considerable amount of research on Hongkongers' code-switching (e.g., Chen 2008). The importance of multilingualism in the city has been magnified beyond its actual interplay with broader historical reality and the development of Hongkongers' lifeworlds.

This paper aims at giving a longitudinal, illustrative account of Hong Kong multilingualism from a socio-historical perspective. It primarily focuses on the development of the three languages in formal aspects, secondarily on their whereabouts in daily life. The sources to be used are mainly from historical reality and authoritative monographs, including credible scholarly publications and official reports from the Hong Kong government. While it mentions education in passing, the body draws attention to various levels of social events and collective lifestyles in Hong Kong, arguing that the city is leaving monolingualism but has yet to achieve multilingualism. Since the history of diglossia (or triglossia) in Hong Kong spans more than a century, the discussions below are selective. 


\section{Cantonese, English, Putonghua in the early colonial period of Hong Kong}

When Hong Kong ${ }^{1}$ became a colony of the British Empire after the First Opium War in 1842 and the Second Opium War in 1860, it was a fishing village on the east of South China. The vast majority of inhabitants spoke Yue dialects (e.g., Weitou dialect) and other Chinese varieties (e.g., Hakka and Teochew). Some merchants on the coast also used Chinese Pidgin English. Upon the British settlers' arrival, Hong Kong was made a free port where the economy improved rapidly. Thanks to business opportunities, English-speaking Indians were attracted and migrated to Hong Kong.

Emigrants from the neighboring cities, who hoped for a better working environment and a higher living standard, also started to migrate to Hong Kong. Most of them were descendants of Guangdong Chinese, who spoke Cantonese and wrote vernacular Chinese ${ }^{2}$ (Chen 2008). The Cantonese-speaking Chinese dominated in the population within a few decades. Although the colonial government allocated officials from its colonies in the Indian subcontinent to Hong Kong, these South Asians were mainly responsible for maintaining public security and fighting corruption (Bhowmik \& Kennedy 2017). The ethnic minorities, who spoke English and other South Asian languages (e.g., Urdu and Hindi), worked and lived separately from the Chinese (Lam \& Lee 2013). This was why Hong Kong had been nearly "racially homogeneous" (Gibbson 1987, p.1; cf. Bacon-Shone \& Bolton 1998).

In the late 19th century, the increase in the Chinese population in Hong Kong contributed to the British Parliament's concerns about establishing Chinese schools in the city (Lu 2005). However, the colonial government did not intervene in the situation until a pestilence outbreak in Hong Kong in 1894 (known as the Third Pandemic). From May to November that year, Hongkongers failed to effectively communicate with the English officials; as a consequence, they did not understand the importance of environmental hygiene, which caused serious sanitary problems and over 2400 deaths (see Pryor 1975). The tragedy motivated the promotion of language education in Hong Kong. Instead of investing in more Chinese schools, though, the government decided to allocate more resources to set up English schools to increase the size of the local elites who would be capable of working with the British officials (Sweeting 1990).

A short review of the historical reality of Hong Kong indicates the essence of Cantonese as the home language, the perceptual value of English as the supreme language in official domains, and the otherness of Putonghua as the national language used in the distant motherland. While Cantonese (the in-group language) was loaded with affective meanings, English and Putonghua (the out-group languages) were learnt for the practical reason of access to the community of government officials or the upper ruling class. This background shaped the developments of the three languages in Hong Kong from the early 20th century onward.

\section{The development of Cantonese, English, and Putonghua in Hong Kong's formal settings}

This section will delineate the development of the linguistic profile of the three languages in Hong Kong, focusing on the governmental, legal, and other workplace domains. Historical events in the education domain that had a significant impact on these domains will be mentioned in passing. The discussion of each period starts and ends with a description of how the period was characterized by a particular linguistic phenomenon.

\footnotetext{
${ }^{1}$ Hong Kong refers to Hong Kong Island, Kowloon Peninsula, and the New Territories. Hong Kong Island was perpetually ceded to the United Kingdom under the terms of the Treaty of Nanking after the First Opium War. The colony was expanded to part of Kowloon Peninsula under the terms of the Convention of Peking after the Second Opium War. It was further expanded to the New Territories (inclu ding some outlying islands) under the terms of the Convention for the Extension of Hong Kong Territory in 1898.

${ }^{2}$ Cantonese is a southern Chinese dialect that is largely unintelligible with Putong hua, and written vernacular Chinese (i.e. baihuawen) is the basis of Standard Modem Chinese, which is quite different from written Cantonese in terms of vocabulary and grammar (Gibbons 1987). Historically, most Hongkongers acquired a Chinese dialect as a first language but learned to write a standard variety likea second language (Lord \& T'sou 1985).
} 


\subsection{From the 1900 s to the early $1960 \mathrm{~s}$}

These six decades could be considered as a period of early industrialization in which few Hongkongers made their lives with English, but many of them expressed a preference for investing in English for the next generation. In the early 1900s, over $81 \%$ of Hongkongers spoke Cantonese (Hong Kong Government, 1986). English was limited to the upper class only (Lin \& Man 2009; Lu, 2005). However, the establishment of The University of Hong Kong (HKU), the first university in the city where English was the medium of instruction (EMI), rendered Hong Kong adults aware of the critical role of English in social mobility. Although the number of Englishspeaking Hongkongers remained very low in the 1930s, they foresaw the importance of English in career prospects.

During World War Two, Hong Kong was occupied by Japan from late December 1941 to late August 1945. Although Japanese was the official language and English was banned in this period, the spread of Japanese was not successful in general (see Higuchi \& Kwong 2012 for a detailed discussion). After the Communist Party of China (CPC) took over Mainland China and established the People's Republic of China (PRC) in 1949, many refugees came from China to Hong Kong to avoid persecution. The non-Cantonese tended to give up their own mother tongues to learn to use Cantonese (Higuchi \& Kwong 2012). To prevent any problems resulting from the sudden population growth, the colonial government hired Gurkhas from Nepal to patrol and deal with the influx of refugees (Lam \& Lee 2013). These refugees, together with the ethnic minorities, brought a strong workforce to the textile, manufacturing, and building industries (Schenk 2001). Whereas working in these fields did not require English skills (Li 2017), the resulting economic boom enabled Hong Kong parents to afford to send their children to EMI schools. In particular, when they realized that even the would-be first university where Chinese was the medium of instruction (CMI) - The Chinese University of Hong Kong (CUHK) - reluctantly adopted EMI in most classes (Liu 1988), they believed that English and EMI were the keys to post-secondary studies and promising jobs.

Key milestones: From the 1900s to the early 1960s, Cantonese was mainly used for a livelihood when Hongkongers went about work, which was semi-skilled or unskilled in nature. As the economic growth was not directly driven by the use of English, there was no immediate need to know English. Nevertheless, as English was used in tertiary education, not to mention the fact that it was the sole official language in the civil service, Hongkongers realized that mastery of English would help them climb the social ladder.

\subsection{From the mid-1960s to the early 1980s}

These 15 years can be considered as a period of rapid industrialization and urbanization in which Cantonese gained co-official status, and Chinese-English code-mixing emerged in Hong Kong. Although the colony was not affected by the unstable political movements driven by the CPC (Gu 2011; Pierson 1998), the Leftist Riots broke out in May 1967. In response to the Cultural Revolution on the mainland, pro-communists in Hong Kong demonstrated against the British government and resorted to bomb attacks against it. After the riots, Great Britain saw the need for social reforms by language planning. The British officials were unlikely to learn Cantonese, a difficult tonal language for them. To improve her relationship with the public, however, the colonial government accorded Chinese a co-official status in 1974 (Liu 1988). Whereas it avoided clearly defining "Chinese", it acknowledged both spoken Cantonese and Standard Written Chinese ${ }^{3}$ as an official language of Hong Kong ${ }^{4}$. Cantonese was not only used as a working language in the civil service (Gibbons, 1987) but also enjoyed more official prestige in other formal settings (Pennington 1998). However, this change did not influence the dominant role of English in the civil service, where senior positions were still occupied by Englishspeaking expatriates. There was an influx of Vietnamese refugees to Hong Kong during the Vietnam War, but

\footnotetext{
${ }^{3}$ The understanding of "Chinese" in Hong Kong is ambiguous. In Chinese communities worldwide, "Chinese" normally refers to Putonghua (and its simplified written form), the national standard variety of Chinese (Pierson 1998). In addition, when Standard Chinese is written in Hong Kong, it is presented in the traditional form.

${ }^{4}$ Dialects other than Cantonese had disappeared in Hong Kong schooling and most workplaces by that time (Gibbons 1987).
} 
they lived in a geographically segregated region, so their language hardly had any great impact on the two official languages.

On the other side of the increase in the status of Chinese was the emergence of code-mixing. EMI schools had been sought after since the early 1950s, but many EMI school teachers actually taught in English supplemented with a considerable amount of Cantonese (Johnson \& Lee 1987). The result was that their students' exposure to English was not as substantial as expected. Although the mixed code was not officially recommended (Liu 1988), it mirrored the linguistic landscape in Hong Kong workplaces at that time, shaping students' future use of codemixing in non-classroom settings (Li 1996; cf. Poon 1998). As Kwok and Chan (1972) observed, HKU students had started to mix their Cantonese conversations with English words since the early 1970s (cf. Luke \& Richards 1982). These elites were likely to practice code-mixing after graduating from college and joining the workforce.

Key milestones: From the mid-1960 to the early 1980s, the asymmetry between Chinese and English seemed to be reduced. Both languages started to be used together in educational and other work settings. The phenomenon was a possible signal of inching towards bilingualism.

\subsection{From the mid-1980s to the late 1980s}

In these few years the value of bilingual competence was overtly increased in Hong Kong. Despite the official status of Chinese, the perennial dominance of English in official domains had construed the perception that English had the most desirable capital in career advancement (Gu 2011). The Pearl of the Orient was said to be a cradle of English professionals. As Lord (1984) ventured, "[t]here can be few places in the world where a higher standard of English as a second language amongst the professional and business classes in Hong Kong can be found" (p.9). In 1984, however, Britain failed to renew the lease of Hong Kong with Beijing, which meant that Hong Kong would be returned to China in $1997^{5}$. After the Sino-British Joint Declaration, many Hong Kong elites opted to migrate to English-speaking countries for a presumably stable socio-political environment (Chen 2008). The colonial government was then concerned about the social roles of Chinese and English again (Liu 1988; Pierson 1998). It decided to make Hong Kong a bilingual city where Chinese and English diffused into all aspects.

The colonial government implemented several policies to achieve this ultimate goal. Since 1984, governmental departments had recruited more English-speaking Hongkongers to take up leading positions in the civil service (Lin \& Man 2009). In 1987, the Official Languages Ordinance also announced that all new legislation should be enacted in both English and Chinese. With respect to education, the government appropriated more funding to the tertiary institutions other than HKU and CUHK for cultivating more high-educated bilinguals (Shive 1992). It continued to covertly tolerate the mixed code used in secondary schools, of which over $90 \%$ were EMI in nature (Evans 2013; cf. Li 2017). On the other hand, it declared official assistance to CMI schools, part of which provided regular Putonghua classes to students (Pierson 1998). All these aimed to normalize the co-existence of Chinese and English in Hong Kong.

Key milestones: From the mid-1980s to the late 1980s, there was increasing recruitment of local English professionals and strict enforcement of bilingual legislation in Hong Kong. More Hong Kong adults with bilingual proficiency gained access to the ruling circle. While educational measures were more favourable to students from higher social backgrounds, they increased the instances of addressing both Chinese and English in teaching and learning activities. Students were prepared for the functional roles of the two (or three) languages in Hong Kong. The citizens were convinced that handling both languages would be the gateway to success.

\subsection{From the 1990s to mid-1997}

These few years before the handover could be considered as a period of deindustrialization and commercialization in which English and Putonghua became apparently loaded with economic status in Hong

\footnotetext{
${ }^{5}$ The United Kingdom agreed to transfer the whole colony (including the ceded regions) to China.
} 
Kong. Since the late 1980s, Hong Kong had moved to a service-oriented and knowledge-based economy and a cosmopolitan city of foreign trading (Li 2017). In turn, English became widely used in trading firms and wholesale companies where locals, expatriates, and overseas partners interacted frequently (Tsang 2004). As more and more English-speaking Hong Kong merchants earned high incomes, the middle-class recognized that English would help to build commercial relationships and wealth in addition to social status.

Across the border, China had reopened its "door" under the leadership of Deng Xiaoping since 1978. As labour costs remained low, from the late 1980s many Hong Kong businessmen who were involved in foreign trading had set up or relocated their factories on the mainland. This gradually increased the importance of Putonghua for trading purposes (Lai 2001). In the mid-1990s, there was even a time in which people wondered if Putonghua would enjoy equal status with English (Evans et al. 1998) or replace English to be the language of success in the future (Pierson 1998). Thanks to business with China, Putonghua became another economically beneficial device co-existing with English.

Key milestones: The trading and logistic industries consolidated the status of English in Hong Kong. Simultaneously, at least those who were associated with China business had a renascent interest in learning Putonghua. More and more adults deemed the two languages to be sources of livelihood.

\subsection{From the transfer of sovereignty to the mid-2000s}

This period was characterized by the condition that English was considered as the taken-for-granted indicator of international competitiveness and Putonghua as the powerful turbines for business in collaboration with China. On 1 July 1997 the PRC regained sovereignty over Hong Kong. The city became a Special Administrative Region (SAR) under the "One Country, Two Systems" policy, which maintained its ideological ties to the Englishspeaking western world (Wang, Shao \& Li 2010). The ruling class in the SAR government was mostly formed by elites with Chinese business or political background. Since they had benefited from the tacit understanding that English was the language of success, they emphasized the need to maintain Hong Kong's status as an international financial and business center by increasing citizens' English standards. As a result, English even appeared more important in the workplace than it was in the colonial period (Lin \& Man 2009). It was a "prerequisite for employment in the upper echelons of the public sector and the business and professional worlds" (Evans 2013, p.303).

The importance of English in post-colonial Hong Kong, however, contradicted the new mandatory guideline on the MoI for secondary schools. In September 1998, the SAR government issued a mandatory guideline on the MoI for secondary schools. Only 114 secondary schools were allowed to continue using EMI from secondary one to secondary three ${ }^{6}$. The remainder had to use CMI to teach content subjects. This guideline somewhat made a return to the elite education system in the early colonial period, and it was not supported by parents and the commercial world (Poon 1999). One year later, the SAR government put forward the "biliterate and trilingual policy" as a remedy. The aspiration aimed at making secondary school graduates who were "truly biliterate and trilingual" (see HKSAR Government 1999, p.23): able to speak Cantonese, English, and Putonghua and to write Standard Modern Chinese and Standard English. As Cantonese was the home language of most students, the outcome of this policy was schools' putting more manpower and capital to English and Putonghua. It also inevitably marginalized the ethnic minorities, who received little support in Chinese education (Gu \& Patkin 2013).

When the SAR government launched the biliterate and trilingual policy, it also hoped to "adopt Putonghua as the MoI in the Chinese Language Education" (Curriculum Development Council 1999, p.9). Whereas the attempt was so controversial that it was tentatively put aside (see Shao 2016), the role of Putonghua was recognized after China gained access to the World Trade Organization (WTO) in December 2001. Since then, Hong Kong

\footnotetext{
${ }^{6}$ As secondary four to secondary seven was beyond free compulsory education provided by the government, schools were allowed to continue using CMI or to change to EMI based on their local contexts. Factors ranged from students' general English proficiency to the intended leaming outcomes of a subject.
} 
was the nexus between the mainland and the world (Chiang 2016). Many Hong Kong bilinguals were sent back to the mainland to help in management. The use of Putonghua in employment suddenly increased with the contact between Hong Kong and the mainland (Wang \& Kirkpatrick 2013; also see Ortmann 2015).

Key milestones: Although Cantonese was still the lingua franca of Hongkongers in the early post-colonial years, English and Putonghua won out in both the workplace and educational domains. They allowed people to navigate commerce and bureaucracy. Their existing or new positions in international and Chinese business resulted in another important step to trilingualism.

\subsection{From the mid-2000s to the late 2000s}

Starting from the mid-2000s, Putonghua was believed to be part of the linguistic repertoire parallel with English for maintaining the economic growth and prosperity of Hong Kong. After the outbreak of severe acute respiratory syndrome (SARS) in 2003, the SAR government and Beijing implemented a series of policies to reactivate the services sector. One of them was the Individual Visit Scheme, which aimed at stimulating inbound tourism by motivating mainlanders to travel to Hong Kong (Chiang 2016). In consequence, Putonghua was considered yielding immediate, maximal economic benefits, and therefore worth learning (Evans 2013). In 2006, up to $40.2 \%$ of the Hong Kong population knew Putonghua (Hong Kong Government 2006). Its ceremonial role in formal events was on the increase. Yet, Putonghua and English were alike in the situation that both languages lacked a widely-accepted pedagogy to teach or an authentic setting to use (Lu 2005; Wang \& Kirkpatrick 2013). Although they were promoted almost in every discipline, few Hongkongers really accomplished the goal of being biliterate and trilingual (Li 2017).

In mid-2009, the SAR government launched the fine-tuning MoI policy to revamp the English education system. Heads of secondary schools were granted authority to make their own decision on MoI (Education Bureau 2009). This laissez-faire policy motivated a return to the mixed code used in the colonial period (Evans 2013). Secondary schools were enabled to simulate most social contexts in Hong Kong, where the three languages co-existed asymmetrically. Except in university (where English remained largely dominant over Chinese), Hong Kong teenagers became more open and less hostile to mix them in use for social interaction.

Key milestones: With the prosperity of China-related business, Putonghua became important in tourism, the hospitality industry, and the retail business. Cantonese as the medium of communication lost ground to Putonghua in workplaces that mainly served mainland tourists, who often could not understand Cantonese fully. As the mixed code regained its popularity in class, the time for Hong Kong youngsters to simultaneously use Cantonese and English increased.

\subsection{From the early 2010 s to the late 2010 s}

This period can be summarized as follows: Use of Cantonese, English, and Putonghua played their functional but complementary roles. As the Great Recession from 2008 to 2013 did not change Hong Kong's status of capitalistic trading and financial centre, the city remained closely tied to international commerce (Adams \& Wong 2015). English maintained its high, dominant role in the civil service, professional arenas, and most white collar workplaces (Evans 2010). Notwithstanding, according to the Census and Statistics Department (2012a), only $3.5 \%$ of the Hong Kong population often spoke English. This meant that extensive practice of oral English was uncommon. Hong Kong still lacked a general, immediate physical environment for speaking English. Cantonese was still the unmarked choice of spoken communication (Evans, 2010).

Although Cantonese had never changed its role as a lingua franca, its economic value already lagged behind Putonghua. Apart from the tourism-related fields, new development strategies planned by the PRC, such as The Belt and Road Initiative (Hong Kong's Information Services Department 2017a) and the Guangdong-Hong Kong-Macao Bay Area Development (Hong Kong's Information Services Department 2017b), largely favored English-Putonghua bilinguals. These would make Putonghua more critical in career prospects. Since Hong Kong had experienced a growing proportion of the young labor force knowing English and Putonghua, the economic 
importance of the two-second languages became a matter of fact (Gu \& Tong 2012). However, the ethnic minorities, which had risen to 8\% of the total Hong Kong population in 2016 (Census and Statistics Department 2017), did not share the linguistic capital of Putonghua because few of them could master Chinese, especially Chinese literacy (Bhowmik \& Kennedy 2017). They tended to use their own first languages or, if necessary, accented Englishes at work, blue-collar, and low-skilled (Gu \& Patkin 2013).

Key milestone: Cantonese was the "practical capital at work", but English and Putonghua were the symbolic capital for work.

\subsection{A brief and interpretive summary}

The review on how the three languages have developed in relatively formal settings in Hong Kong reveals the following phenomena:

English used to be an official working language in legal and governmental settings only, but it has extended to business-related workplaces through economic force since the 1980s. Most Hongkongers have positively correlated English to international competiveness, career opportunities, and abilities to move upwards in the social hierarchy. Nowadays, most educated Hongkongers can understand and produce some English, but they rarely use it in intra-ethnic workplace communication, let alone mastering it up to native standard.

Cantonese, as the mother tongue of the mainstream community, has never ceased to be the medium of oral communication in most Hong Kong settings. However, although the pragmatic value of Cantonese is high, it has been suppressed in the official written and educational settings, and it is not explicitly acknowledged by Hongkongers. Since the 1997 handover, Cantonese has gradually fallen behind Putonghua in socio-economic development as it does not yield value-added advantages in the workplace.

Putonghua used to be a peripheral language in most workplace settings, but it has never ceased to exist due to its correspondence to Standard Modern Chinese, the co-official written language of Hong Kong since 1974. Since the transfer of sovereignty, the Hong Kong economy has increasingly relied on China-associated business, and Putonghua has been loaded with economic value and political meaning in ceremonial occasions. Under the biliterate and trilingual policy, Putonghua is a core subject for the younger generation.

The heritage languages of the ethnic minorities were mainly used in intra-ethnic communication throughout the colonial period. After the handover, especially since the 2010s, the number of refugees from South Asian regions has been soaring. They seldom possess knowledge of Chinese, their learning of Cantonese or Putonghua is limited, and they often rely on their first languages plus accented Englishes. Their languages, however, have never had any official status in Hong Kong.

It can be seen from this summary that, for Hongkongers, English and Putonghua are economically important but not necessary for survival, and that Cantonese is mostly useful for survival but not for economic development. This situation is accompanied by the fact that English and Putonghua represent symbolic capital for career advancement, while Cantonese is the device for social interaction. The three languages coexist in the international financial and business center, where people not only need a convenient tool for communication but also want competitive commodities for high income and a positive city image. Other languages do exist, but their roles and developments are inconsequential in most official domains.

\section{The development of Cantonese, English, and Putonghua in Hong Kong's informal settings}

This section will delineate the development of the linguistic profile of the three languages, focusing on the daily life of Hongkongers. The discussion of each period again starts and ends with a description of how the period was characterized by a particular linguistic phenomenon. 


\subsection{From the 1900s to the early 1970 s}

In these seven decades, Hongkongers mainly spoke Cantonese but used Cantonese, English, and Putonghua for entertainment. Cantonese was the language spoken at home, in other daily routines, and during Chinese festivals, and Standard Modern Chinese was used in most written and print settings (Li 2017) (except for some showbiz news and soft porn sections in the newspaper ${ }^{7}$ ). Japanese began to be a language of entertainment during the period of Japanese occupation (Higuchi \& Kwong 2012). While Cantonese opera films gained their popularity in the 1950s (Chen 2014), English and Putonghua also permeated the popular culture in Hong Kong. As English had been a desirable language to master since the early 20th century, English songs became popular for English-knowing teenagers (Chik 2010). In addition, an increasing number of Putonghua-speaking Chinese came from China to Hong Kong (mainly through illegal immigration) after 1951. These refugees enjoyed Putonghua films and Putonghua songs, which came with a sense of belonging, in pursuit of leisure (Pierson 1998), so there was a small boom of Putonghua in the 1960s (Higuchi \& Kwong 2012).

Key milestone: Both Hongkongers and new arrivals were exposed to the three languages, Cantonese being the primary one, in their spare time.

\subsection{From the mid-1970s to the mid-1980s}

This decade or so was characterized by the dominance of Cantonese over English and Putonghua as the medium of entertainment and the emergence of Hong Kong English in the community of the middle class. Thanks to the fact that the Chinese gained its co-official status in 1974, Hongkongers started to articulate their values and beliefs deliberately in their mother tongue during leisure time (Chen 2008). Cantonese songs (e.g., Sam Hui) hence developed rapidly to express the voices, thoughts, and culture of Hong kongers themselves (Chik 2010). By contrast, Putonghua lost its attractiveness and played a peripheral role in people's lifestyles. With respect to English, mass education motivated Hongkongers, especially the elite students who affirmed a more western identity, to integrate the language into their conversation to varying degrees. This integration gave birth to "Hong Kong English", which was "derived from the interaction of Cantonese and English spoken by native Cantonese speakers and from the social, cultural and psychological forces which bear on the acquisition of English" (Hunter 1974, p.17). It was considered a step towards the outer circle (Karchu 1985), but it was perceived to be impure and indicative of low English standards (Sung 2014).

Key milestone: Cantonese further generated a sense of belonging to the public in its own right and its influence on English.

\subsection{From the late 1980s to mid-1997}

With the prosperity of Hong Kong, the upper-middle-class (or above) afforded to have more experience with oral English in daily life, and the general public could gain access to different languages in the mass media. The elite developed a westernized lifestyle where English was part of their everyday conversations (Yau 1988). Many parents from the upper-middle class (or above) sent their children to international schools, which mostly admitted non-Chinese (Afendras 1998). Not only did these children live their school life in an English environment, but their parents had more contact with other parents who were English speakers (e.g., in church, after school). Furthermore, wealthy families could hire domestic helpers from the Philippines, Thailand, and Indonesia (Evans 2011). These caregivers were "live-in English tutors" to enhance the English environment for their children at home (Afendras 1998, p.137). English hence was no longer the colonizer's language only (Pennington \& Yue 1994). Other normal citizens might not afford to have such attainment (Lai 2001), but they could watch free English channels with bilingual broadcasting (e.g., TVB Pearl) (Pierson 1998), read English comics with parallel Chinese translation (e.g., Snoopy) (Bacon-Shone \& Bolton 1998), and hear Cantonese songs mixed with English and Japanese lyrics (e.g., the Four Heavenly Kings) (Chik 2010). Japanese (e.g., Hong Kong

7 Even in these sections, written Cantonese was used with quotation marks to indicate its "provisional and stigmatized status" (Higuchi $\&$ Kwong 2012, p.5). 
Post) and Korean newspapers (e.g., Wednesday Journal) also appeared. Alongside these entertainment domains was the establishment of STAR TV, which made Putonghua songs, dramas, and showbiz programs easily accessible again. A Putonghua language channel was even established by Radio Television Hong Kong (RTHK) on 31 March 1997 (Wilkinson \& Chen 2001).

Key milestone: The accessibility of all the three languages provided Hongkongers with hands-on or psychological experience with a multilingual context.

\subsection{From the transfer of sovereignty to the mid-2000s}

Putonghua exercised its influence on Hongkongers' lifestyles in the early post-colonial years. After the handover, Cantonese (mixed with a little Hong Kong English) remained the main medium for intra-ethnic communication (Chen 2008; Lai 2001). People who came to Hong Kong for educational or career achievements needed to learn Cantonese for daily communication (Lu 2005). However, with the steady and significant increase in Mainland university students (especially at the postgraduate level), Putonghua was used when they interacted with Hongkongers in social activities ${ }^{8}$. In the mass media, there was also Putonghua television news and Putonghua dramas (though Cantonese dubbed) brought from Mainland China. These were intended to help lower-educated new immigrants from Mainland China (who came to Hong Kong through the One-way Permit ${ }^{9}$ ) integrate to the city (Wilkinson \& Chen 2001). The Putonghua news allowed them to catch up with the current affairs happening in Hong Kong; the China dramas helped them learn Cantonese through listening to the scripts and reading the subtitles (which were in Standard Chinese). Additionally, Nepalese Newspapers (e.g., Sunrise Weekly Hong Kong) that served the descendants of Gurkhas, who returned to Hong Kong after the handover but hardly knew Chinese, also appeared.

Key milestone: The pool of Putonghua-speaking people and their influence on Hongkongers' language use were gradually enlarged in different domains.

\subsection{From the late-2000s to the early 2010s}

Thanks to the rapid development of information technology, the mixed code of English, Standard Modern Chinese, and written Cantonese gained popularity in computer-mediated communication. The Internet and the smartphone opened the door to the world out there. Hongkongers could access enormous amounts of textual and audio-visual English and Putonghua materials for infotainment. Simultaneously, information communication technology provided them with a convenient platform to interact with each other in the three languages. Apart from Standard Chinese and English, Hongkongers also input written Cantonese when interacting with each other online (Yip \& Matthews 2017). Although code-mixing and written Cantonese were stigmatized at all official levels (Gibbons 1983; Li 2006), technology normalized the practices in the daily communication of Hongkongers (see Lam 2010; Li et al. 2016).

Key milestone: At least on the digital platform, Hongkongers experienced or experimented with the three languages creatively or strategically.

\subsection{From the mid-2010s to the late 2010s}

Hongkongers tried to redefine the roles and positions of Cantonese and Putonghua in recent years. Hongkongers remained ideologically attached to English for social mobility (Gu \& Tong 2012). While they became open to other languages (e.g., Korean) for simulating a multicultural origin and global perspectives, they developed mixed feelings towards Cantonese and Putonghua. After the Umbrella Movement in 2014, the tension between the SAR government and the teenagers or young adults exploded into the Hong Kong-

\footnotetext{
8 In many circumstances the two parties did not share a Chinese language, and they might resort to speak English.

9 The One-way Permit was an official document issued by the PRC to allow Mainland Chinese citizens to emigrate to Hong Kong or Macau. Typical applicants were Mainlanders whose immediate family members were already Hong Kong Permanent Residents.
} 
Mainland China Conflict (Ortmann 2015) (e.g., The 2016 Mong Kok civil unrest, The 2019 Hong Kong antiextradition bill protests, the debate over cross-border closures during the outbreak of Coronavirus disease in early 2020). Owing to social problems that were perceived to stem from low-skilled mainlanders, there was an increasing strain between Cantonese-speaking Hongkongers and Putonghua-speaking people, especially new arrivals, parallel traders, and inbound tourists from the mainland (Li 2016). This antagonistic relation was reflected in Hongkongers' attitudes towards Cantonese and Putonghua, which could signal the difference between the locally-born Hongkongers and other Chinese (Gu 2010). They not only considered Putonghua not their language, but also practiced online shaming against the Putonghua-accented Cantonese speakers who had misbehaved in public domains (cf. Gu \& Tong 2012). Yet, the paradigm might not apply to the ethnic minorities since only $6 \%$ of them had a home environment in which to use Chinese (Census and Statistics Department 2012b). Even at school, the children maintained their heritage languages with their co-ethnic peers (Lai, Gao, \& Wang 2015). But despite their segregated lives, some of them were distorted (often by the press) to be the origins of street disturbance (see Jackson \& Nestervoa 2017), so their heritage languages were loaded with negative connotations to some Hong Kong racists.

Key milestones: While Putonghua is almost a must in the workplace and educational domains, Hongkongers emphasized that Cantonese should be locally prestigious in daily life. Putonghua is somewhat perceived to be a threat to Hong Kong core values, and the way Hongkongers live their lives.

\subsection{A brief and interpretive summary}

The review on how the three languages have developed in relatively informal settings in Hong Kong reveals the following phenomena:

English has been, since the 1980s, a language accompanying overt prestige in daily communication for the upper-middle-class or above, but the general public is unlikely to abandon Cantonese as the channel for intraethnic communication. Outside the classroom or workplace, the majority of Hongkongers have found no tangible goal in speaking (or writing) English only, though it has been easily accessible in the media since the 1950s.

Cantonese has been, since the mid-1970s, both the resourceful language for communication and the major language for entertainment. For the majority of Hongkongers, Cantonese mixed with a little English is a popular form of speech in face-to-face or digital communication, despite criticism from commentators or the mass media. Recently, it is even loaded with more emotional value due to Hongkongers' hostility towards new arrivals and mainland tourists.

Putonghua, since the end of the colonial period, has seen its influence on daily life widened through the mass media, mainland students, and new immigrants. That said, Hongkongers have seldom opted for Putonghua conversation unless necessary. For the majority of locally-born Hongkongers, Putonghua carries almost no sense of belonging but connotations of both social-economic capital and socio-cultural problems in the last decade.

The first languages of the ethnic minorities have been used in their home domain and other community-based activities. However, these activities rarely involve Cantonese-speaking Hongkongers. As the mass media tend to report biased news on South Asian refugees in a negative frame, their languages sometimes trigger negative feelings to outsiders.

It can be seen from this summary that Hongkongers' daily life is primarily occupied by Cantonese, secondarily English, and Putonghua as a distant third. Languages of the ethnic minorities are limited to their personal lives, which seldom intersect with those of the majority of Hongkongers. People's constant exposure to and personal experiences with English and Putonghua, especially their experiences in producing it with their parents, siblings, and peers, are limited and often supported by Cantonese. In particular, full English immersion is only reserved for the upper class. The three languages coexist in Hongkongers' lifestyles, where Cantonese is liable to use though English and Putonghua are not easy to completely avoid. 


\section{Conclusion}

The above descriptions and evaluations of how the three languages developed in Hong Kong have shown that the British colonization from 1842 to 1997 did not bring Hongkongers much interaction with English speakers, and that the political transformation in 1997 has not made them truly identify with Putonghua. Regardless of their political ties with the ruling communities, both languages need to be learnt or mastered - but are not often used in social interaction. In particular, their functional roles in oral settings remain undefined outside the classroom, which keeps their distance from the lingua franca and codification. The mainstream community has little parental involvement when using them. The roles of other languages are even more trivial. As a consequence, no languages have ever threatened or taken over the position of Cantonese in intra-ethnic (spoken) communication across most settings in Hong Kong.

On the other side, Hong Kong has developed to a business-oriented international city where Cantonese is mostly inferior to English and Putonghua in socio-economic development. In a nutshell, these two languages directly contribute to the financial status of Hong Kong that attracts transnational companies and Chinese business investment. They are often considered indispensable for livelihood improvement and sustainable economic growth, so English and Putonghua are not exactly foreign languages (as they are in Russia, for example). By contrast, the value of Cantonese for developing Hong Kong is very limited in today's knowledge-based economy. For Hongkongers, knowing Cantonese is considered a requirement for living and socializing - but knowing Cantonese only is not enough for them to aim high, which often means making more money, having more status, and gaining more power. Therefore, in many formal settings, English and Putonghua enjoy higher prestige than Cantonese, though they are actually less pragmatic or convenient for Cantonese-speaking Hongkongers.

In concluding, this article proposes that the imbalance among Cantonese, English, and Putonghua in Hong Kong constitutes the current linguistic situation: While English and Putonghua are more than foreign languages but less than a common second language, Cantonese is the first language that is commonly used but officially powerless across several generations. Such a situation can be traced back to different but intertwined sociohistorical roots upon a discourse-driven analysis. For the majority of Hongkongers, who strive for both economic well-being and convenience of life, none of the three languages could be neglected or given up, and none of them alone could guarantee success for all aspects. Other languages may add value to their linguistic capital, but normally there is no immediate need or strong incentive to learn them. Hong Kong, so to speak, is still a metropolis in between monolingualism and multilingualism, however, slowly inching towards the latter with digitalization and globalization.

\section{References}

1. Adams, J., \& Wong, Y. C. A. (2015). Hong Kong and Shanghai: Current and/or future international financial centers? Journal of Chinese Economic and Foreign Trade Studies, 8(3), 183-193.

\section{https://doi.org/10.1108/JCEFTS-07-2015-0019}

2. Afendras, E. A. (1998). The onset of bilingualism in Hong Kong: Language choice in the home domain. In: M. C. Pennington (Ed.), Language in Hong Kong at century's end (pp. 131-141.). Hong Kong: Hong Kong University Press.

3. Bacon-Shone, J., \& Bolton, K. (1998). Charting multilingualism: Language censuses and language surveys in Hong Kong. In: M. C. Pennington (Ed.), Language in Hong Kong at century's end (pp. 43-90). Hong Kong: Hong Kong University Press.

4. Bhowmik, M., \& Kennedy, K. J. (2017). Caught between cultures: Case study of an "out of school" ethnic minority student in Hong Kong. Asia Pacific Journal of Education, 37(1), 69-85. 


\section{https://doi.org/10.1080/02188791.2016.1169991}

5. Bloomfield, L. (1933). Language. New York: Henry Holt.

6. Census and Statistics Department (2012a). 2011 Population census: Summary results. Hong Kong: Government of the Hong Kong Special Administrative Region.

7. Census and Statistics Department (2012b). 2011 Population census thematic report: Ethnic minorities. Hong Kong: Government of the Hong Kong Special Administrative Region. Available at https://www.statistics.gov.hk/pub/B11200622012XXXXB0100.pdf

8. Census and Statistics Department (2017). 2016 Population by-census thematic report: Ethnic minorities. Hong Kong: Government of the Hong Kong Special Administrative Region. Available at https://www.statistics.gov.hk/pub/B11201002016XXXXB0100.pdf

9. Chen, K. H. Y. (2008). Positioning and repositioning: Linguistic practices and identity negotiation of overseas returning bilinguals in Hong Kong. Multilingua, 27(1-2), 57-75. https://doi.org/10.1515/MULTI.2008.004

10. Chen, X. (2014). Affect, folklore, and Cantonese opera film. Journal of Chinese Cinemas, 8(3), 226-243.

11. Chiang, M.-H. (2016). Sustaining Hong Kong's services amid the changing dynamics of China's economy. China Perspectives, 106(2), 37-45. http://doi.org/10.4000/chinaperspectives.6978

12. Chik, A. (2010). Creative multilingualism in Hong Kong popular music. World Englishes, 29(4), 508-522. https://doi.org/10.1111/j.1467-971X.2010.01678.x

13. Curriculum Development Council (1999). A holistic view of the Hong Kong school curriculum proposed reforms. Hong Kong: Printing Department.

14. Education Bureau (2009). Enriching our language environment, realizing our vision: Fine-tuning of the medium of instruction for secondary schools. Hong Kong: Hong Kong Government Printer.

15. Evans, S. (2010). Language in transitional Hong Kong: perspectives from the public and private sectors. Journal of Multilingual and Multicultural Development, 31(4), 347-363.

\section{https://doi.org/10.1080/01434632.2010.497218}

16. Evans, S. (2011). Hong Kong English and the professional world. World Englishes, 30(3), 293-316.

https://doi.org/10.1111/j.1467-971X.2011.01655.x

17. Evans, S. (2013). The long march to Biliteracy and Trilingualism: Language policy in Hong Kong education since the handover. Annual Review of Applied Linguistics, 33, 302-324.

https://doi.org/10.1017/S0267190513000019

18. Evans, S., Jones, R., Rusmin, R. S., \& Cheung, O. L. (1998). Three languages: One future. In: M. C. Pennington (Ed.), Language in Hong Kong at century's end (pp. 391-418). Hong Kong: Hong Kong University Press.

19. Gibbons, J. (1983). Attitudes towards languages and code-mixing in Hong Kong. Journal of Multilingual and Multicultural Development, 4(2/3), 129-147. https://doi.org/10.1080/01434632.1983.9994107 
20. Gibbons, J. (1987). Code-mixing and code choice: A Hong Kong case study. Clevedon: Multilingual Matters.

21. Grosjean, F. (2010). Bilingual: Life and reality. Cambridge: Harvard University Press.

22. Gu, M. M. (2011). Language choice and identity construction in peer interactions: insights from a multilingual university in Hong Kong. Journal of Multilingual and Multicultural Development, 32(1), 1731. https://doi.org/10.1080/01434632.2010.532876

23. Gu, M. M., \& Tong, H. K. (2012). Space, scale, and languages: Identity construction of cross-boundary students in a multilingual university in Hong Kong. Language and Education, 26(6), 505-515.

\section{https://doi.org/10.1080/09500782.2012.663553}

24. Gu, M. M., \& Patkin, J. (2013). Heritage and identity: Ethnic minority students from South Asia in Hong Kong. Linguistics and Education, 24(2), 131-141. https://doi.org/10.1016/j.linged.2012.12.008

25. Higuchi, K., \& Kwong, Y. K. (2012). Multilingual Hong Kong: Language and experience. Nagoya: V2 Solution.

26. Hong Kong Government (1986). Hong Kong census reports 1841 - 1941. Hong Kong: Hong Kong Government Printer.

27. Hong Kong Government (1999). Quality people, quality home: Positioning Hong Kong for the 21st century. Hong Kong: Printing Department.

28. Hong Kong Government (2006). Hong Kong 2006 Population By-census Main Report. Hong Kong: Hong Kong Government Printer.

29. Hong Kong's Information Services Department (2017a, December 14). Belt \& Road deal signed. [online] news.gov.hk. Available at:

http://archive.news.gov.hk/en/categories/admin/html/2017/12/20171214 114143.shtml [Accessed 14 March 2020]

30. Hong Kong's Information Services Department (2017b, November 18). HK signs Guangdong pacts. [online] news.gov.hk. Available at:

http://archive.news.gov.hk/en/categories/admin/html/2017/11/20171118 191436.shtml [Accessed 14 March 2020]

31. Hunter, D. B. (1974). Bilingualism and Hong Kong English. The Educationalist, 5, 15-18.

32. Jackson, L., \& Nestervoa, Y. (2017). Multicultural Hong Kong: Alternative new media representations of ethnic minorities. Multicultural Education Review, 9(2), 93-104.

https://doi.org/10.1080/2005615X.2017.1313021

33. Johnson, R. K., \& Lee, P. L. M. (1987). Modes of instruction: Teaching strategies and student responses. In: R. Lord \& H. N. L. Cheng (Eds.), Language education in Hong Kong (pp. 99-121). Hong Kong: The Chinese University Press.

34. Kachru, B. (1985). Standards, codification, and sociolinguistic realism: The English language in the outer circle. In: R. Quirk \& H. Widdowson (Eds.), English in the world: Teaching and learning the language and literatures (pp. 11-30). Cambridge: Cambridge University Press. 
35. Kwok, H., \& Chan, M. (1972). Were the twain do meet. General Linguistics, 12(2), 63-82.

36. Lai, C., Gao, F., \& Wang, Q. (2015). Bicultural orientation and Chinese language learning among South Asian ethnic minority students in Hong Kong. International Journal of Bilingual Education and Bilingualism, 18(2), 203-224. https://doi.org/10.1080/13670050.2014.887054

37. Lai, M.-L. (2001). Hong Kong students' attitudes towards Cantonese, Putonghua, and English after the change of sovereignty. Journal of Multilingual and Multicultural Development, 22(2), 112-133.

\section{https://doi.org/10.1080/01434630108666428}

38. Lam, M. K. (2010). English-Cantonese code-switching and code-mixing in online chats in Hong Kong. Master dissertation, Department of Linguistics, The University of Hong Kong.

39. Law, K.-Y., \& Lee, K.-M. (2013). Socio-political embeddings of South Asian Ethnic minorities' economic situations in Hong Kong. Journal of Contemporary China, 22(84), 984-1005.

https://doi.org/10.1080/10670564.2013.795312

40. Li, D. C. S. (1996). Issues in bilingualism and biculturalism: A Hong Kong case study. New York: Peter Lang.

41. Li, D. C. S. (2006). Chinese as a lingua franca in greater China. Annual Review of Applied Linguistics, 26, 149-176. https://doi.org/10.1017/S0267190506000080

42. Li, D. C. S. (2017). Multilingual Hong Kong: Languages, literacies, and identities. Cham: Springer.

43. Li, D. C. S., Wong, C. S. P., Leung, W. M., \& Wong, S. T. S. (2016). Facilitation of transference: The case of monosyllabic salience in Hong Kong Cantonese. Linguistics, 54(1), 1-58. https://doi.org/10.1515/ling$\underline{2015-0037}$

44. Li, M. (2016). Pluralistic ignorance in Sino-Hong Kong conflicts: The perception of mainland Chinese people living in Hong Kong. Chinese Journal of Communication, 9(2), 153-172.

\section{https://doi.org/10.1080/17544750.2015.1091021}

45. Lin, A. M. Y., \& Man, E. Y. F. (2009). Bilingual education: Southeast Asian perspectives. Hong Kong: Hong Kong University Press.

46. Liu, C. (1998). Multi-lingual development and language planning in Hong Kong. In: V. Bickley (Ed.), Languages in education in a bi-lingual or multi-lingual setting (pp. 220-227). Hong Kong: Institute of Language in Education.

47. Lord, R. (1984). 1997 and the need for English at that time. Paper presented at a conference on Language Teaching in the Chinese context. Cited in Yau, M. S. (1988). Bilingual education and social class: some speculative observations in the Hong Kong context. Comparative Education, 24(2), 217-227.

\section{https://doi.org/10.1080/0305006880240206}

48. Lord, R., \& T'sou, B. K. (1985). The language bomb. Hong Kong: Longman.

49. Lu, D. H. (2005). An exploration into bilingual education and bilingualism of Hong Kong. Hong Kong: The Joint Publishing (Hong Kong) Company Ltd. 
50. Luke, K. K., \& Richards, J. C. (1982). English in Hong Kong: functions and status. English World-Wide, 3(1), 47-64.

51. Ortmann, S. (2015). The umbrella movement and Hong Kong's protacted democratization process. Asian Affairs, 46(1), 32-50. https://doi.org/10.1080/03068374.2014.994957

52. Pennington, M. C. (1998). Introduction: perspectives on language in Hong Kong at the century's end. In: M. C. Pennington (Ed.), Language in Hong Kong at century's end (pp. 3-40). Hong Kong: Hong Kong University Press.

53. Pennington, M. C., \& Yue, F. (1994). English and Chinese in Hong Kong: Pre-1997 language attitudes. World Englishes, 13(1), 1-20. https://doi.org/10.1111/j.1467-971X.1994.tb00279.x

54. Pérez-Milans, M., \& Soto, C. (2016). Reflexive language and ethnic minority activism in Hong Kong: A trajectory-based analysis. AlLA Review, 29(1), 48-82. https://doi.org/10.1075/aila.29.03per

55. Pierson, H. D. (1998). Societal accommodation to English and Putonghua in Cantonese-speaking Hong Kong. In: M. C. Pennington (Ed.) Language in Hong Kong at century's end (pp. 91-111). Hong Kong: Hong Kong University Press.

56. Poon, A. Y. K. (1998). Bilingualism and monolingualism: A shift in Hong Kong's language in education policy. In: V. Berry \& A. McNeill (Eds.), Policy and practice in language education (pp. 89-104). Hong Kong: Department of Curriculum Studies, The University of Hong Kong.

57. Poon, A. Y. K. (1999). Chinese medium instruction policy and its impact on English learning in post-1997 Hong Kong. International Journal of Bilingual Education and Bilingualism, 2(2), 131-146.

\section{https://doi.org/10.1080/13670059908667684}

58. Pryor, E. G. (1975). The great plague of Hong Kong. Journal of the Hong Kong Branch of the Royal Asiatic Society, 15, 61-70.

59. Schenk, C. R. (2001). Hong Kong, as an international financial centre: Emergence and development, 19451965. London, UK: Routledge.

60. Shao, Q. (2016). Keeping the policy window closed: Framing Putonghua as a medium of instruction in Hong Kong. Asia-Pacific Education Research, 25(5-6), 771-779. https://doi.org/10.1007/s40299-016$\underline{0309-y}$

61. Shive, G. (1992). Education expansion and the labour force. In: G. Postiglione (Ed.), Education and society in Hong Kong: Toward one country and two systems (pp. 215-231). Hong Kong: Hong Kong University Press.

62. Sung, C. C. M. (2014). Accent and identity: exploring the perceptions among bilingual speakers of English as a lingua franca in Hong Kong. International Journal of Bilingual Education and Bilingualism, 17(5), 544557. https://doi.org/10.1080/13670050.2013.837861

63. Sweeting, A. (1990). Education in Hong Kong pre-1841 to 1941: Fact and opinion. Hong Kong: Hong Kong University Press.

64. Tsang, S. Y. S. (2004). A modern history of Hong Kong. Hong Kong: Hong Kong University Press.

65. Wang, L., \& Kirkpatrick, A. (2013). Trilingual education in Hong Kong primary schools: a case study. International Journal of Bilingual Education and Bilingualism, 16(1), 100-116. 
https://doi.org/10.1080/13670050.2012.689479

66. Wang, Q., Shao, Y., \& Li, Y. J. (2010). "My way or mom's way?" The bilingual and bicultural self in Hong Kong Chinese children and adolescents. Child Development, 81(2), 555-567.

\section{https://doi.org/10.1111/j.1467-8624.2009.01415.x}

67. Wilkinson, J. S., \& Chen, L. (2001). Putonghua-language radio programming in Hong Kong: RTHK and the Putonghua audience. Candaian Journal of Communication, 26(1), 143-153.

\section{https://doi.org/10.22230/cjc.2001v26n1a1201}

68. Yau, M. S. (1988). Bilingual education and social class: Some speculative observations in the Hong Kong context. Comparative Education, 24(2), 217-227. https://doi.org/10.1080/0305006880240206

69. Yip, V., \& Matthews, S. (2017). Intermediate Cantonese: A grammar and workbook (2nd ed.). London and New York: Routledge.

\section{Conflicts of Interest}

The author reports no conflicts of interest between the content of this article and any public, commercial, or not-for-profit sectors.

\section{Funding Statement}

This library research received no specific grant from any funding agency in the public, commercial, or not-forprofit sectors. The author alone is responsible for the content and writing of this article.

\section{Acknowledgments}

This article is based on the author's first submission to the edited volume of Multilingual global cities: Singapore, Hong Kong, and Dubai. I am grateful to Prof. Peter Siemund and Dr. Jakob Leimgruber for their feedback on this manuscript before it was excluded from the volume due to irrelevance to the approach to the intended topic. I would like to thank the anonymous reviewer for his or her advice on the contents and layout of the paper as well. Any errors or oversights remaining are my own. 